\title{
Endangerment of Cultural Heritage Sites by Strong Rain
}

\author{
Thomas Krauß and Peter Fischer \\ DLR, Remote Sensing Institute, Münchener Str. 20, 82234 Oberpfaffenhofen, Germany
}

\begin{abstract}
Due to climate change extreme weather conditions become more and more frequent in the last years. Especially in Germany nearly every year a large flood event happens. Most of these events are caused by strong rain. There are at most two causes for these floodings: The first is locally strong rain in the area of damage, the second happens at damage sites located near confluxes and strong rain in the upper stream areas of the joining rivers. The amount of damage is often strongly correlated with unreasonable designation of new construction in such endangered regions. Our presented study is based on an earlier project together with a german insurance company. In this project we analyzed correlations of geographical settings with the insurance data of flood damages over ten years. The result of this study was a strong relation of the terrain with the amount and the probability of damages. Further investigations allow us to derive a system for estimating potential endangerment due to strong rain just from suitable digital terrain models (DTMs). In the presented study we apply this method to different types of cultural heritage $(\mathrm{CH})$ sites in Germany and other parts of the world to detect which type of $\mathrm{CH}$ sites were build with potential endangerment of strong rain events in mind and which ones are prone to such events.
\end{abstract}

Keywords: Strong rain, Cultural Heritage, Digital terrain model

\section{INTRODUCTION}

Beside the threatening of cultural heritage $(\mathrm{CH})$ sites by war and iconoclasts natural disasters are also one of the main dangers for such areas. The International Charter for Space and Major Disasters lists theirs activations by category as shown in fig. $1 .{ }^{1}$ One can see the most listed disasters are due to flooding.

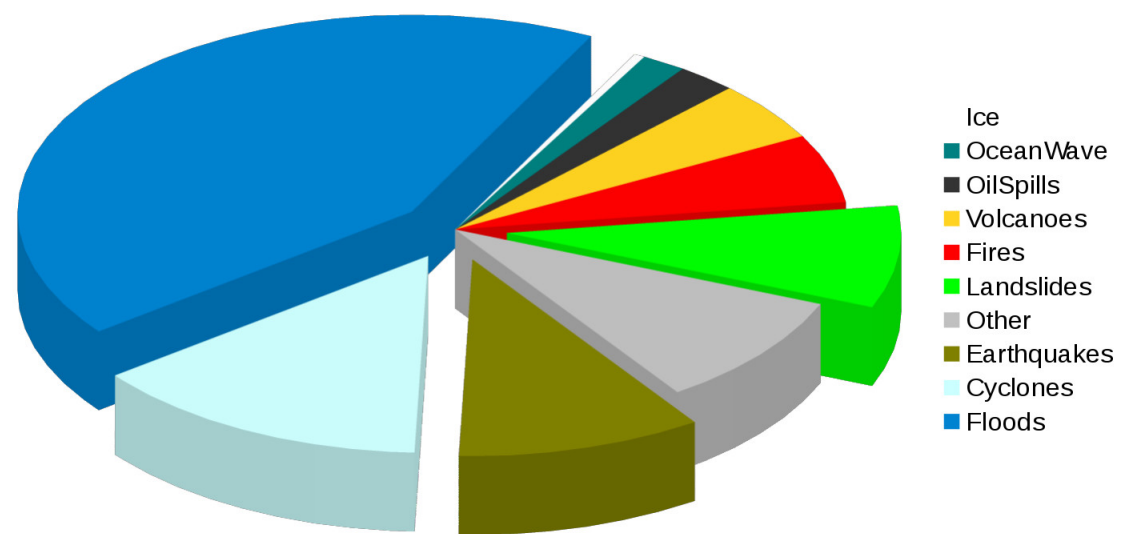

Figure 1: Distribution of disasters as listed with the International Charter for Space and Major Disasters (www.disasterscharter.org) between 11/2000 and 2/2017

In fact there are three different types of the listed flooding events in fig. 1. First are the events near the coast caused by high tides, storm floods or tsunamis. Second are river floods especially in the confluxes of rivers. In this case upstream rain cause floods possibly far away from the rainy area. But our investigations in cooperation with a german insurance company showed a third - until now underestimated - flooding cause: strong rain.

Further author information: (Send correspondence to Thomas Krauß)

E-mail: thomas.krauss@dlr.de 
In Germany insurance companies use already a system for flood prediction. But this system is based only on horizontal and vertical distances to existing rivers and lakes. Since in the area of one company no large rivers exist and all areas where marked "safe" they wondered about many damages caused by floods. In a study conducted by us with them a new approach for detection of areas endangered by heavy rain was proven to give a high correlation of the derived endangered areas and the losses claimed at the insurance company. In this project a method was developed for deriving a risk map of areas endangered by heavy rain. It is mainly based only on medium resolution digital elevation models (DEMs) derived world-wide from space like the SRTM-C-band, ${ }^{2}$ the downsampled EuroMaps-3D-DEM ${ }^{3}$ from the indian Cartosat-P5-satellite or any other DEM representing a digital terrain model resembling ground elevations with a ground sampling distance in the range of about 25 to $30 \mathrm{~m}$. From the DEM so called terrain positioning classes (TPI) were derived and correlated to the existing damage data from the insurance company. So a strong correlation of the TPI classes to the probability of damage as well as the costs of the damage could be found.

In this paper we will present the system we developed and apply the results to cultural heritage $(\mathrm{CH})$ sites in Germany and all around the world to estimate possible endangerment from strong rain for these sites. Also an extension of the method is proposed to take the larger surrounding of the $\mathrm{CH}$ site into account.

\section{METHOD}

Comparing different methods of terrain influence for estimation of the danger caused by strong rain in 4 shows that an approach using the so called terrain positioning index (TPI) as presented in 5 and 6 give the best discrimination results. This index classifies a DEM based on the relative difference between the elevation of a cell $z_{0}$ and the average elevation $\bar{z}$ of a ring $R$ ranging from an inner radius $r_{i}$ to an outer radius $r_{o}$ around the cell as shown in fig. 2:

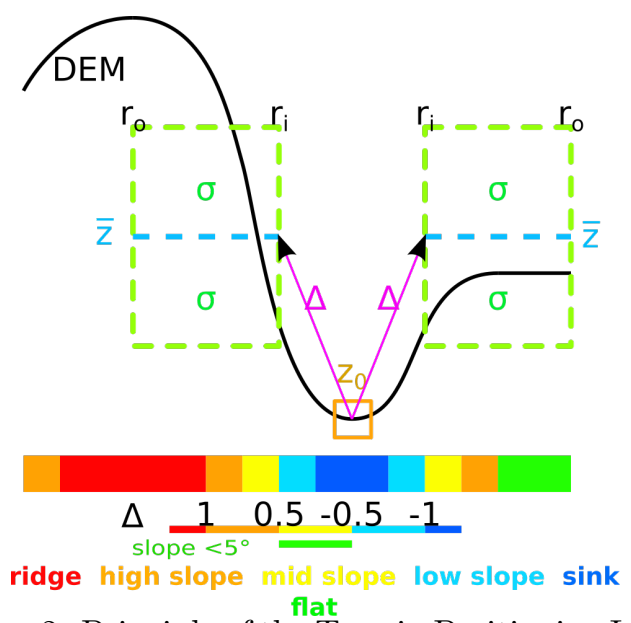

$$
\begin{gathered}
\bar{z}=\frac{1}{N} \sum_{i \in R} z_{i} \quad \sigma=\sqrt{\frac{1}{N-1} \sum_{i \in R}\left(z_{i}-\bar{z}\right)^{2}} \\
\Delta=z_{0}-\bar{z} \quad T P I=\frac{\Delta}{\sigma}
\end{gathered}
$$

Table 1: Definition of the TPI classes

\begin{tabular}{|l|c|c|c|}
\hline Class & $T P I$ & Slope & Color \\
\hline ridge & $1 \leq T P I$ & & red \\
high slope & $0.5 \leq T P I<1$ & & orange \\
mid slope & $-0.5 \leq T P I<0.5$ & $\geq 5^{\circ}$ & yellow \\
flat & $-0.5 \leq T P I<0.5$ & $<5^{\circ}$ & green \\
low slope & $-1 \leq T P I<-0.5$ & & cyan \\
sink & $T P I<-1$ & & blue \\
\hline
\end{tabular}

Figure 2: Principle of the Terrain Positioning Index

In fact the TPI is a classification relative to the standard deviation of the heights in the ring and not using any absolute height differences. For each point of a DEM in a ring $R$ ranging from $r_{i}$ to $r_{o}$ around a DEM point $z_{0}$, the mean $\bar{z}$ and the standard deviation $\sigma$ is calculated. Based on the relative $T P I=\left(z_{0}-\bar{z}\right) / \sigma$ the six classes as shown in tab. 2 are derived.

\section{DATA EVALUATION}

Fig. 3 shows the SRTM DEM (Digital Elevation Model) of the area where reference data from an insurance company were available on the left side. Every green dot represents an insured household, every red dot a damage claim caused by water in the time span between June 2003 and September 2013. The ellipsoidal heights range from 25 to $188 \mathrm{~m}$. The test area is $30 \mathrm{~km} \times 40 \mathrm{~km}$, covering longitudes $6.85^{\circ} \mathrm{E}$ to $7.35^{\circ} \mathrm{E}$ and latitudes $51.30^{\circ} \mathrm{N}$ to $51.67^{\circ} \mathrm{N}$. The right map in Fig. 3 shows an example of the classification of the test area. The colors used are the same as listed in tab. 2 or fig. 2 . 

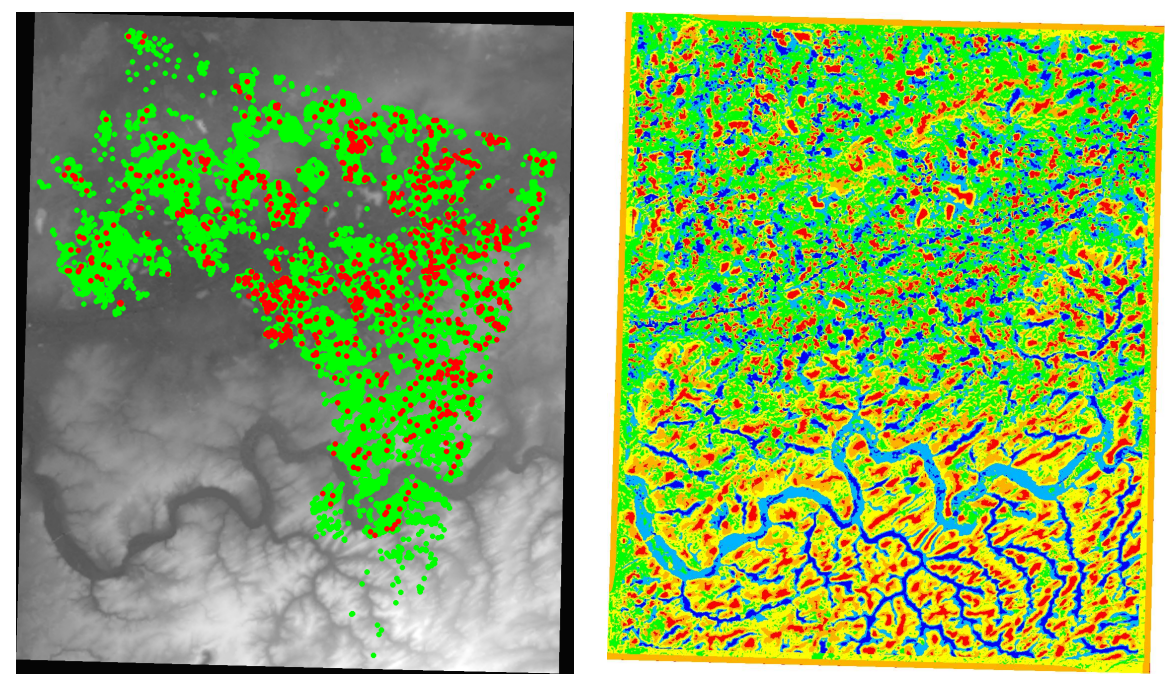

Figure 3: left: SRTM-DEM of test area, $30 \mathrm{~km} \times 40 \mathrm{~km}$, green dots represent insured households, red dots households affected by flood events, right: TPI calculated for the test area, for the class colors please refer to tab. 2 or fig. 2

Deriving the TPI classes for a set of inner radii $r_{i}$ ranging from 30 to $270 \mathrm{~m}$ and outer radii ro from $r_{i}+30 \mathrm{~m}$ up to $1100 \mathrm{~m}$ on the given DEM allows us to find the optimum radii configuration. Calculating the losses per insured household for each class and from these the largest variance over the classes shows an optimum for $r_{i}=90 \mathrm{~m}$ and $r_{o}=750 \mathrm{~m}$. The results for these values are shown in fig. 4, left. The average losses in Euro per class are shown in red (left axis), the percentage of affected households per class are shown in blue (right axis) and the absolute numbers of insured households of the reference data per class are shown above the blue bars.
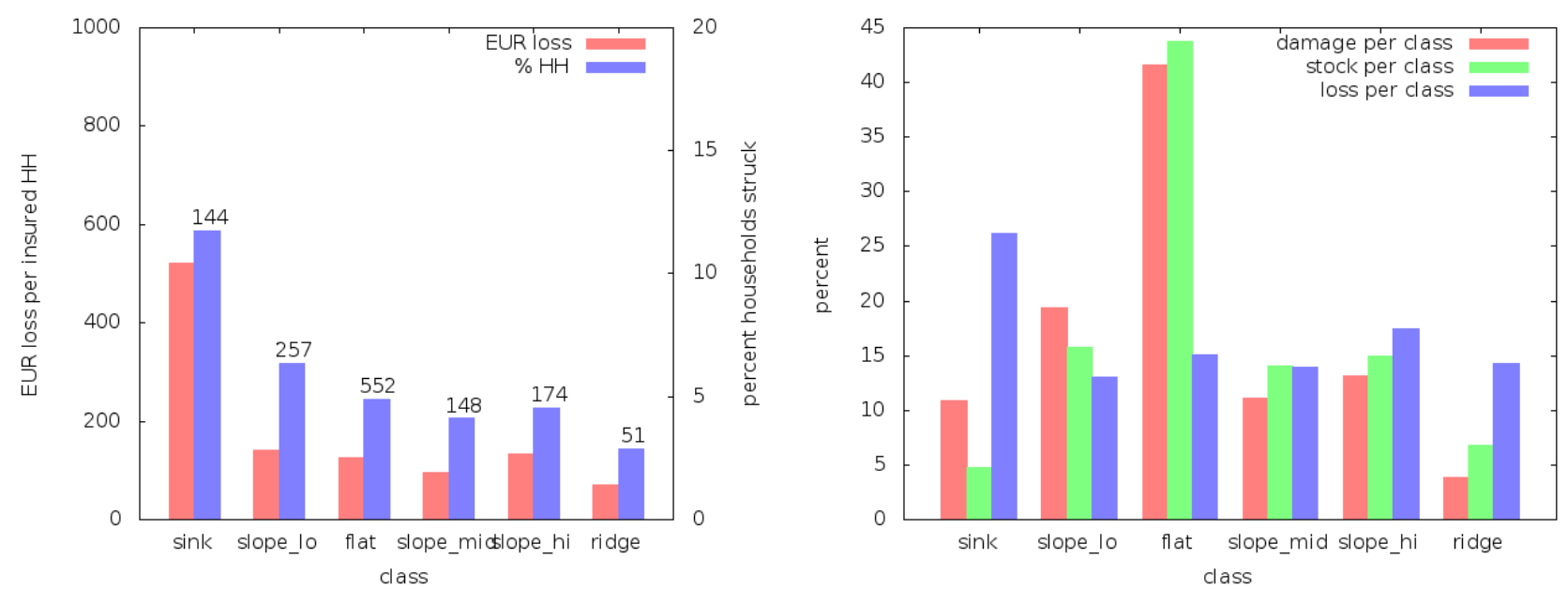

Figure 4: left: Optimum TPI found for $r_{i}=90 \mathrm{~m}, r_{o}=750 \mathrm{~m}$, EUR loss per class (red), percentage of households affected per class (blue) and absolute number of households per class (number above blue bar); right: Percentages of number of damages (red), number of households (green) and loss in Euro (blue) per TPI class for optimum radii combination of $r_{i}=90 \mathrm{~m}$ and $r_{o}=750 \mathrm{~m}$

Fig. 4, right, shows the percentages over all data per class. The percentage of the number of damages in red, the percentage of the absolute number of insured households in green and the percentage of the losses in Euro are shown in blue - all for the found optimum radii combination of $r_{i}=90 \mathrm{~m}$ and $r_{o}=750 \mathrm{~m}$. As can be seen in the sink-class there are only about 5 percent of all households but 10 percent of damages and even more than 25 percent of the monetary losses. 
Since the evaluation was conducted only on a small area in Germany we can not guarantee the applicability of the method world wide, but as a first approach for classifying endangered areas it will be a good choice. The resulting classification is only based on probabilistic approaches using different DEMs of resolutions ranging from $5 \mathrm{~m}$ (EuroMaps 3D) to $90 \mathrm{~m}$ (SRTM C-band). If the DEMs contain errors - e.g. missing or wrong data as known in the SRTM products - the results of such areas are also prone to errors. The resulting map also only tells that there will be a possible danger in case of a strong rain event. So in areas where no rain occurs, there will be also no danger. The danger-map also ranges not from "no damage possible" to "sure damage" but only from "possibility of a damage in 10 years is $3 \%$ " to "12\%". Damages due to strong rain can occur everywhere, only the probability how often they occur is predicted by our damage maps.

Our practical experiences show that areas which are marked dark blue and light blue are prone to damage by strong rain whereas all other areas are reasonably secure. Compare for this also fig. 4, right, which shows that for these two classes the percentage of a damage per class is bigger than the percentage of households in this class.

Applying the TPI to different DEMs from $5 \mathrm{~m}$ to $90 \mathrm{~m}$ (see above) shows overall nearly an complete independence from the resolution of the DEM. It's only important to use a terrain model (DTM) and not a digital surface model (DSM). So we propose the usage of the free 30-m-/1-arcsec-SRTM-DEM. ${ }^{2}$

\section{ENDANGERMENT OF CULTURAL HERITAGE SITES}

For analysing the endangerment of cultural heritage $(\mathrm{CH})$ sites the list of World Heritage sites from the Unesco ${ }^{7}$ is used. It contains different types of cultural sites: single cultural monuments (like churches, buildings or city centers), different monuments or larger areas (e.g. thematic combinations like the "Luther Memorials in Eisleben and Wittenberg" or the "Upper Rhine Valley") and cross-nation wide monuments (like the "Frontiers of the Roman Empire" or "Prehistoric Pile Dwellings around the Alps").

\subsection{Cultural Heritage Sites in Germany}

Table 2: Single cultural monuments in Germany listed in the WHC list of the Unesco grouped by building, city centers and parks

\begin{tabular}{|r|r|l|r|r|}
\hline WHC-ID & Year & Description & Longitude & Latitude \\
\hline 3 & 1978 & Aachen Cathedral & 6.08444444440 & 50.7744444400 \\
271 & 1983 & Pilgrimage Church of Wies & 10.9001388900 & 47.6812777800 \\
292 & 1996 & Cologne Cathedral & 6.9572222220 & 50.9411111100 \\
546 & 1993 & Maulbronn Monastery Complex & 8.8130600000 & 49.0008300000 \\
\hline 272 & 1987 & Hanseatic City of Lübeck & 10.6916700000 & 53.8666700000 \\
624 & 1993 & Town of Bamberg & 10.8888888900 & 49.8916666700 \\
846 & 1998 & Classical Weimar & 11.3286100000 & 50.9775000000 \\
1087 & 2004 & Town Hall and Roland on the Marketplace of Bremen & 8.8074722220 & 53.0759722200 \\
\hline 1127 & 2004 & Muskauer Park / Park Mużakowski & 14.7264444400 & 51.5793055600 \\
\hline
\end{tabular}

Fig. 5 shows the derived SRTM-DEMs for the german WHC sites listed in tab. 2. The coordinates of the Muskau Park region had been corrected to lon/lat $14.723285^{\circ} / 51.549984^{\circ}$ since the location provided in the list was wrong. Also for most of the other sites the listed coordinates and the real position of the object differ slightly but only by about $100 \mathrm{~m}$. All DEMs and thereof derived TPI images shown below cover an area of $2 \mathrm{~km} \times 2 \mathrm{~km}$ if not stated otherwise. The coordinate provided in tab. 2 is always the center of the image (for Muskau the above mentioned corrected coordinate).

In fact we can apply our method only to areas where the provided coordinates correspond to the eligible monument. So we select from the 38 german $\mathrm{CH}$ sites the ones listed in tab. 2 for our investigations.

Fig. 5 shows the SRTM-DEMs of the nine sites used for TPI calculation. The color ranges of the DEMs are adapted to the individual height range as provided below the DEMs. 

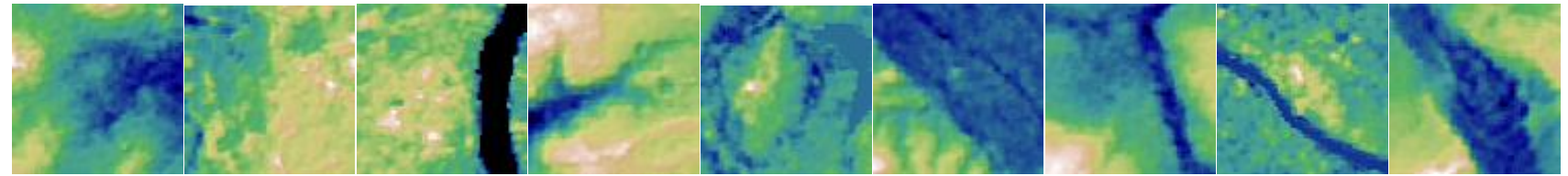

Aachen $(203-273 \mathrm{~m}) \quad$ Wies $(878-944 \mathrm{~m}) \quad$ Cologne $(82-115 \mathrm{~m}) \quad$ Maulbronn $(289-383 \mathrm{~m}) \quad$ Lübeck (35-73 m) Bamberg (276-367 m) Weimar (253-325 m) Bremen (38-69 m) Muskau (142-205 m)

Figure 5: SRTM-DEMs for sites in tab. 2, each $2 \mathrm{~km} \times 2 \mathrm{~km}$, color scaled to provided ellipsoidal height range
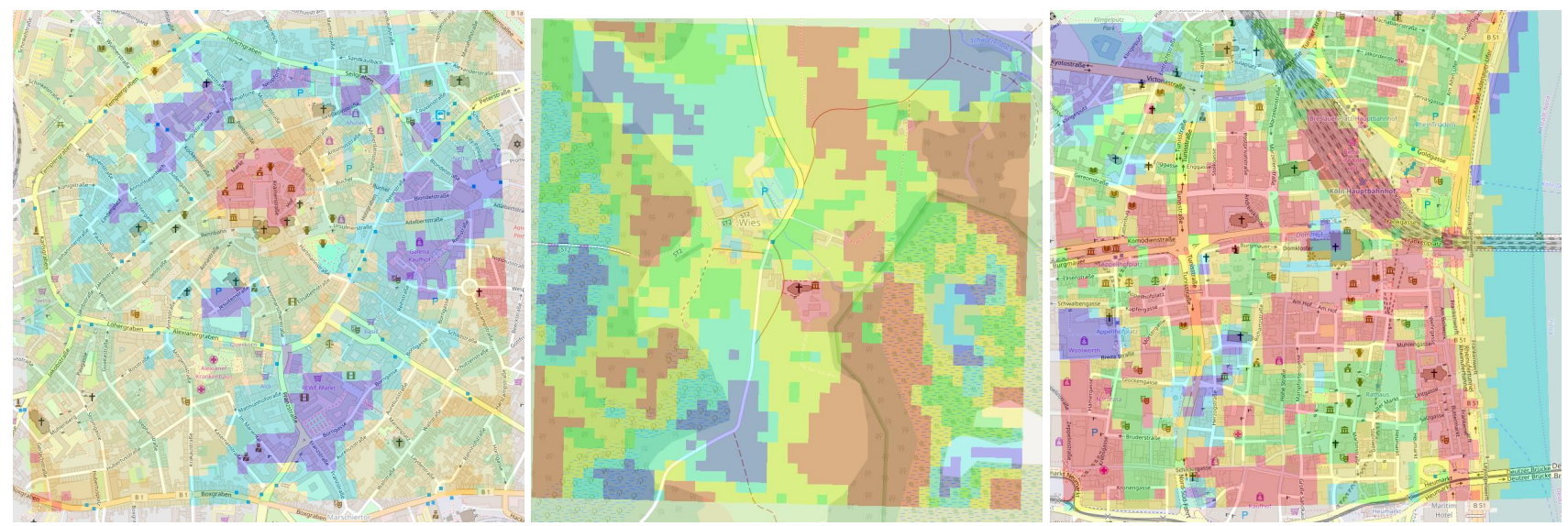

Figure 6: Calculated TPI maps for Aachen, Pilgrimage Church of Wies, Cologne Cathedral

Figs. 6 through 8 show the derived TPI classes for the german WHC sites as listed in tab. 2. The class colors are the same as used in tab. 2 or fig. 2. The TPI class images are overlayed on the corresponding OpenStreetMaps ${ }^{8}$ map.

As can be seen in fig. 6 the cathedrals and churches of Aachen, Cologne and Wies are build on locally higher areas marked in reddish colors at the centers of the TPI images. Comparing these to the Monastery of Maulbronn in fig. 7 (leftmost) shows in contrast that the monastery lies in a valley of a river and is classified as mostly endangered.
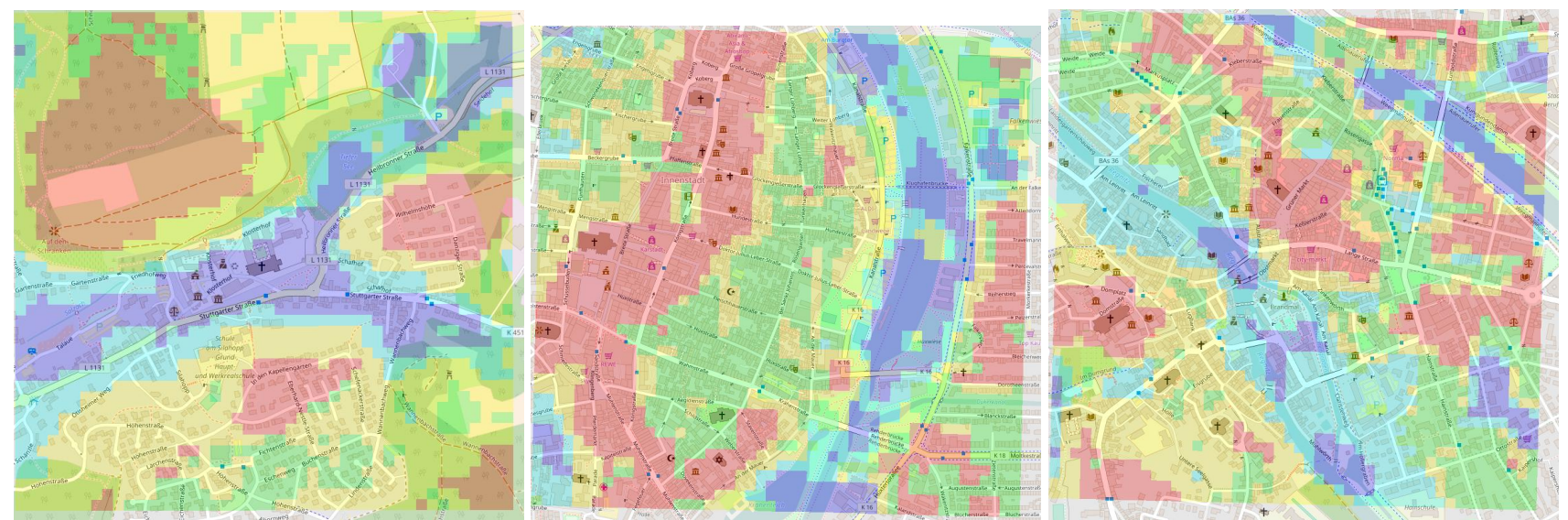

Figure 7: Calculated TPI maps for Maulbronn, Lübeck, Bamberg

The city-centers of Lübeck, Bamberg (fig. 7, right), Weimar and Bremen (fig. 8, left) are all located near rivers which are classified as highly endangered due to the locally lower setting than the city centers. But the city-centers themselves - especially the main old churches - are all classified as "safe" ridge-areas (red).

The final site - the gardens in Muskau ("Fürst Pückler Park", fig. 8, right) - is located on the border to Poland which is marked by the river Neiße as can be seen in the top right of the TPI image. As showed in the DEM (fig. 5) the whole area is nearly on the niveau of the river. But the TPI image reveals that the castle is 

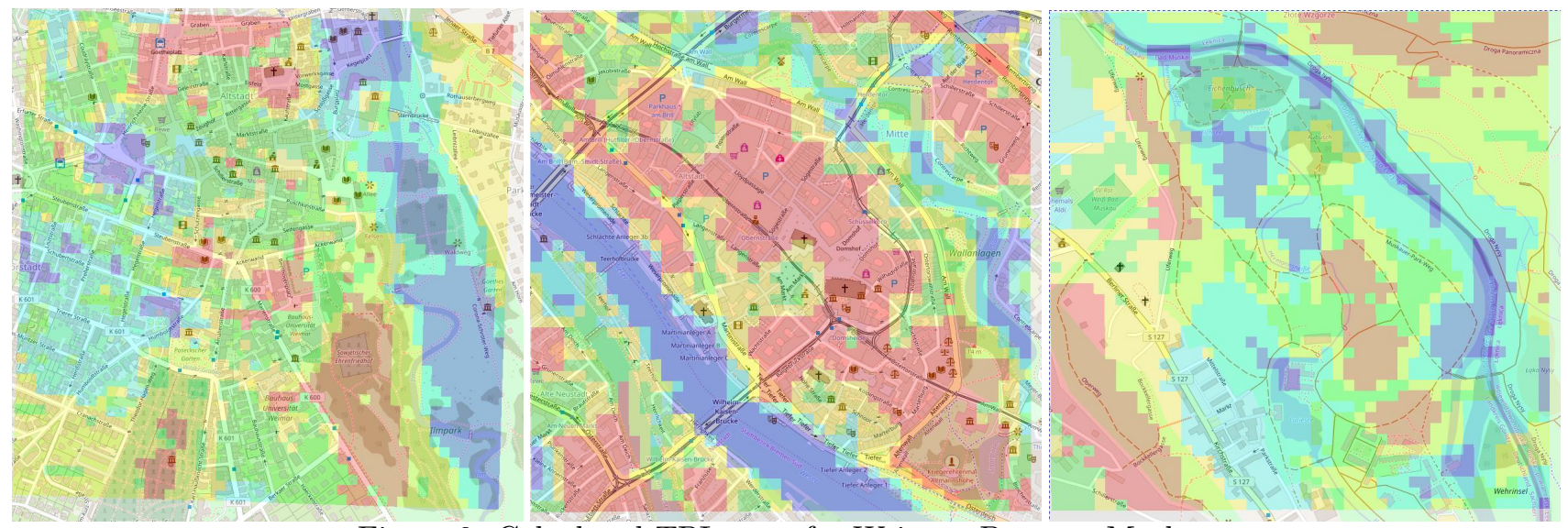

Figure 8: Calculated TPI maps for Weimar, Bremen, Muskau

located nearly fully in the dark blue area (sink!) below the center of the TPI image and is highly endangered by strong rain.

Finally for the investigated german world heritage sites it can be clearly derived that old churches and thus also the correlated city centers are mostly build on local ridge areas to be prepared for strong rain events. Other sites like the Maulbronn monastery or the castle in the Muskau park are in contrast build in highly endangered sink areas. Such monuments should be investigated and secured against strong rain events which will cause more probably high damage.

\subsection{Cultural Heritage Sites in Cyprus}

Table 3 shows the world heritage sites in Cyprus. There are only three sites: the old city of Paphos with the Mosaics, the monasteries and churches in the Troodos region and the prehistoric site in Choirokoitia.

Table 3: Cyprus world heritage of culture sites

\begin{tabular}{|r|r|l|r|r|}
\hline WHC-ID & Year & Description & Longitude & Latitude \\
\hline 79 & 1980 & Paphos & 32.4055600000 & 34.7583300000 \\
351 & 1985 & Painted Churches in the Troodos Region & 33.0958333300 & 34.9202777800 \\
848 & 1998 & Choirokoitia & 33.3433300000 & 34.7983300000 \\
\hline
\end{tabular}
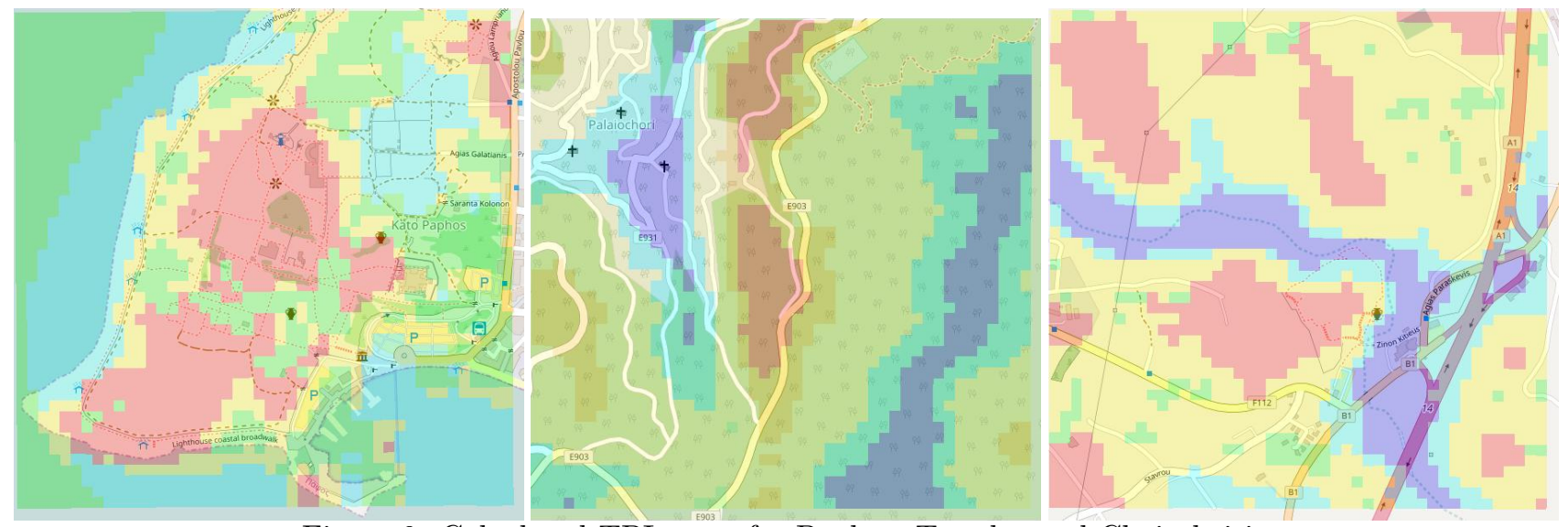

Figure 9: Calculated TPI maps for Paphos, Troodos and Choirokoitia 
In fig. 9 the calculated TPI maps are shown. The old Paphos area near the sea is classified as not prone to strong rain effects since mostly build on local ridge structures. In contrast the churches and monasteries depicted in the Troodos region are build again - as the monastery of Maulbronn above - in a zone endangered by strong rain events. The prehistoric site of Choirokoitia is also locally raised and so only has a lower probability of endangerment by strong rain.

\subsection{Cultural Heritage Sites beyond Europe}

Table 4: CH sites beyond Europe

\begin{tabular}{|r|r|l|l|r|r|}
\hline WHC-ID & Year & Description & Country & Longitude & Latitude \\
\hline 23 & 1980 & Palmyra & Syria & 38.26667000 & 34.55417000 \\
252 & 1983 & Taj Mahal & India & 78.04222000 & 27.17417000 \\
274 & 1983 & Historic Sanctuary of Machu Picchu & Peru & -72.58333333 & -13.11666667 \\
330 & 1985 & Chavin (Archaeological Site) & Peru & -77.17845350 & -9.59277254 \\
441 & 1987 & Mausoleum of the First Qin Emperor & China & 109.10000000 & 34.38333333 \\
592 & 1991 & Borobudur Temple Compounds & Indonesia & 110.20361000 & -7.60778000 \\
700 & 1994 & Lines and Geoglyphs of Nasca and Palpa & Peru & -75.14861000 & -14.72583000 \\
\hline
\end{tabular}

As first example for a site beyond Europe Palmyra was selected beyond others (see tab. 4). Fig. 10 shows the calculated TPI map (here an area of $4 \mathrm{~km} \times 4 \mathrm{~km}$ ) and the SRTM-DEM used for TPI-calculation. As can be seen the Temple of Bel (large red area right of the image center) lies on a locally higher area. The tombs to the left are located mostly on the mid slopes but also remnants can be found in the endangered blue areas.
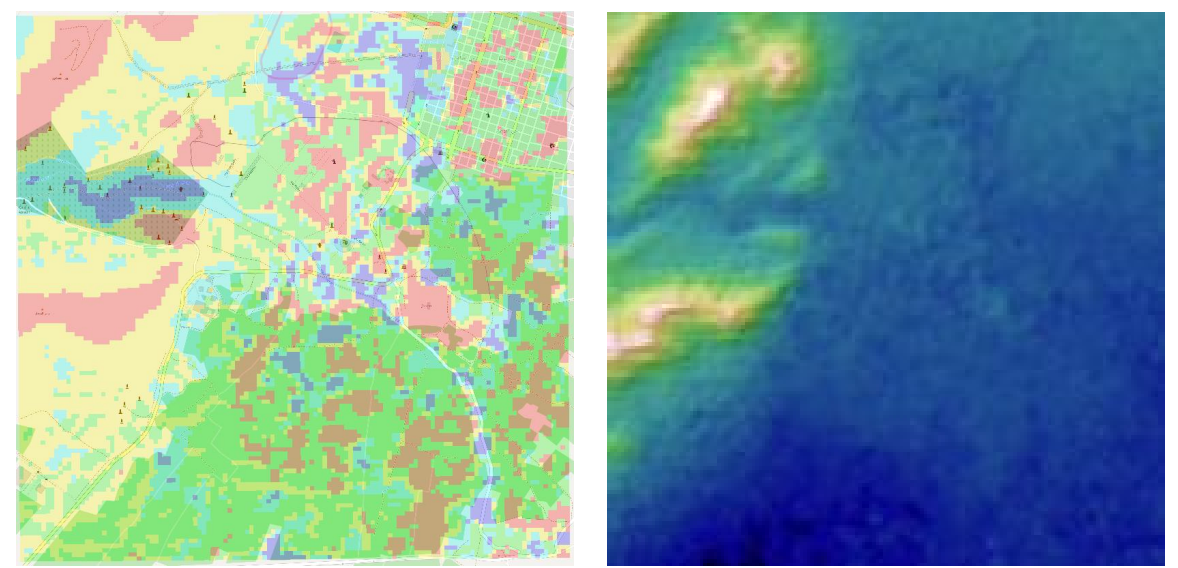

Figure 10: Calculated TPI map for Palmyra, $4 \mathrm{~km} \times 4 \mathrm{~km}$ and associated DEM

The DEM in the right part of the area is nearly flat whereas the left part is hilly. In flat parts even small variations in elevation result in big differences of TPI - the crumble pattern on the right. Since the TPI is a relative measure of local deviations in a ring around the place of subject small height differences are already sufficient to raise a place to a secure "ridge" or drop it down to an endangered "sink". If there is not too much rain it accumulates in such small sinks. But if the rain gets too strong the full plain area may be flooded and thus also the local "ridges".

For such cases there should be an extension of the presented method also taking into account a kind of absolute height above the surrounding - or better some measure how much precipitation is needed to flood also the small ridge areas in a plain.

Figs. 11 through 13 show the TPI maps for the Taj Mahal and the Mausoleum of the First Qin Emperor, Chavin and Borobudur or Nasca and Machu Picchu together with their SRTM-DEMs. It was found that the coordinates of Machu Picchu and Nasca were wrong in the WHC list. These were corrected to lon/lat $-72.548482^{\circ}$ 

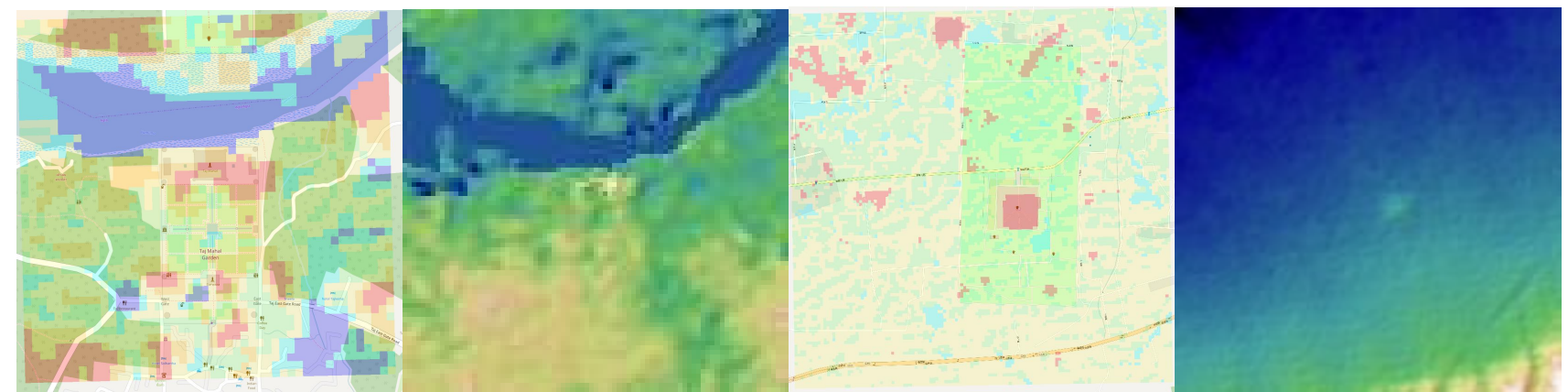

Figure 11: Calculated TPI maps for Agra (Taj Mahal) and the Mausoleum of Qin, $2 \mathrm{~km} \times 2 \mathrm{~km}$ each and associated DEMs ranging from 87-130 and 379-747 $\mathrm{m}$ respectively

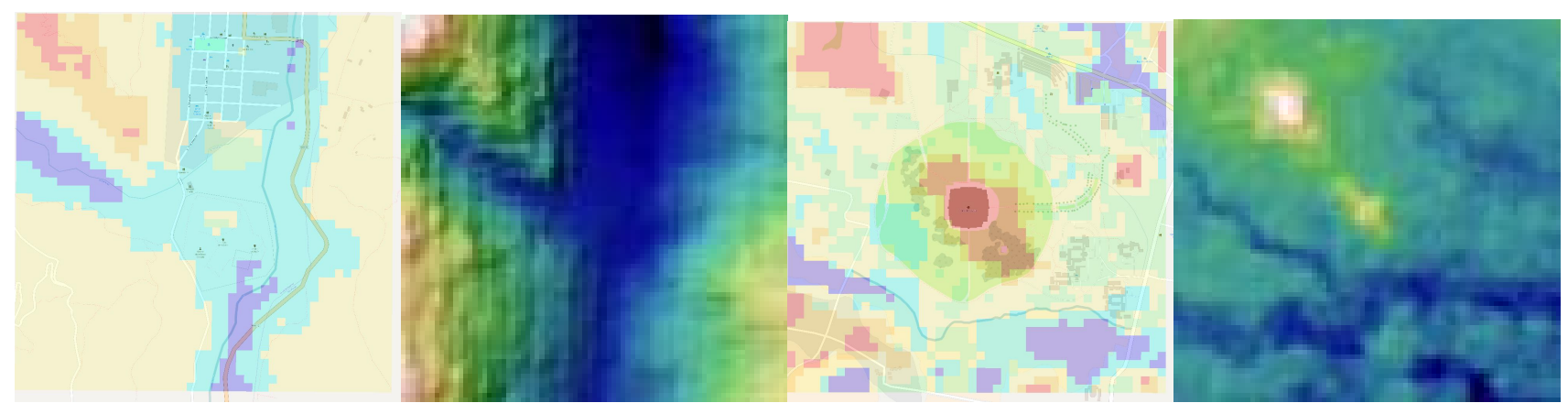

Figure 12: Calculated TPI maps for Chavin and Borobudur, $2 \mathrm{~km} \times 2 \mathrm{~km}$ each and associated DEMs ranging from $3147-3730$ and $254-319 \mathrm{~m}$ respectively

$-13.1627964^{\circ}$ and $-75.175388^{\circ}-14.6929784^{\circ}$ respectively. As can be seen from the TPI (and also already from the DEM) the archeological site of Chavin lies in a river valley and is heavily endangered whereas the Temple of Borobudur and Machu Picchu are situated at local ridges with very unlikely flooding damages. Nasca again is a plain with the spotted pattern due to small sink- and ridge-structures in the TPI. The Taj Mahal is situated securely above the Yamuna river and the Mausoleum of the First Qin Emperor also secure in a slightly slanted plain.

\section{CONCLUSION AND OUTLOOK}

In this work we presented a method which can be used for quickly estimating the vulnerability of areas endangered by heavy rain. The method is based only on a digital terrain model with resolutions of about $30 \mathrm{~m}$ which exist almost for most of the world. Applying the Terrain Positioning Index (TPI) with previously determined general parameters gives a vulnerability classification in six classes ranging from sink over low, mid and high slope to ridges. The probability of the occurance of damage in a time span of ten years drops from $12 \%$ to $3 \%$ for sites with same climate conditions as in Germany where the results of the method were verified.

The probability of getting struck by strong rain depends on (a) the topography as described with the TPI and (b) on the local climate. So in dry regions just the probability of strong rain events is lower but the fact that a specific place is prone to a damage due to strong rain still remains.

Comparing the TPI maps of churches, temples, city centers and monasteries show that old churches, temples or even city centers are mostly erected on locally elevated places whereas monasteries often lie in lower, possibly endangered settings.

Just taking into account the classes in a surrounding of about $50 \mathrm{~m}$ around the investigated object and finding one of the two most endangered classes (sink, low slope) should lead to a closer inspection and possibly taking measures for securing the site against possible strong rain damages.

In future applications based only on the DEM also other natural threats for cultural heritage sites like landslides, tsunamis, cyclones, strong tides (for sites near the sea) or danger from storm may be detected. 

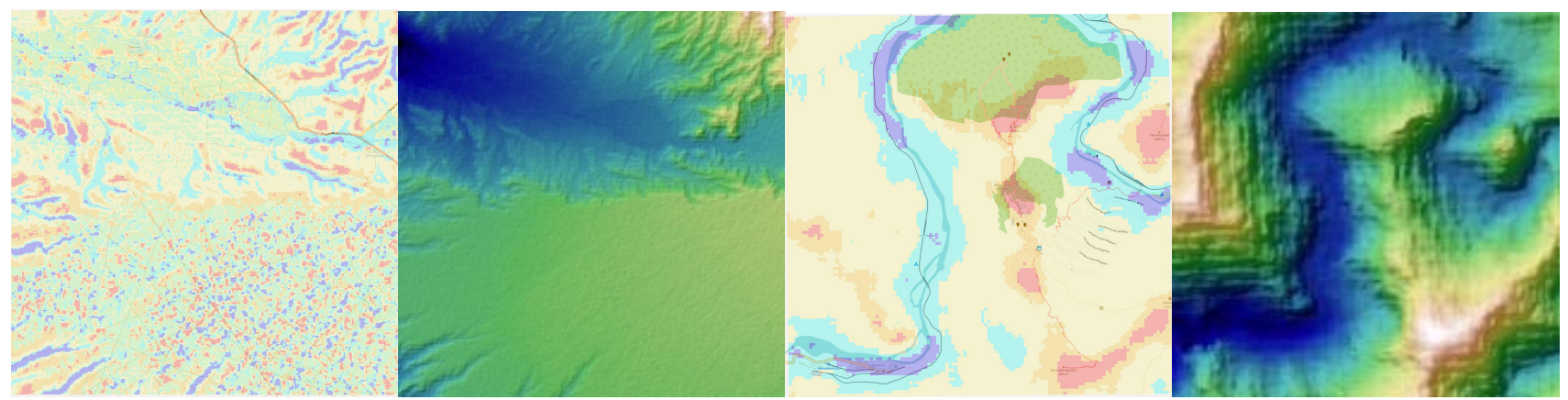

Figure 13: Calculated TPI map for Nasca $(5 \mathrm{~km} \times 5 \mathrm{~km})$ and Machu Picchu $(2 \mathrm{~km} \times 2 \mathrm{~km})$ and associated DEMs ranging from $256-655$ and $1794-3046 \mathrm{~m}$ respectively

\section{REFERENCES}

[1] "International Charter on Space and Major Disasters." http://www.disasterscharter.org/ (2 2017). (accessed $2 / 2017)$.

[2] "SRTM, Shuttle Radar Topography Mission." https://lta.cr.usgs.gov/SRTM1Arc (2 2017). (accessed 2/2017).

[3] "Euro Maps 3D." http://www.euromap.de/products/prod_008.html (2 2017). (accessed 2/2017).

[4] Krauß, T. and Fischer, P., "Automatic Detection and Vulnerability Analysis of Areas endangered by Heavy Rain," in [Proceedings of European Space Agency, Living Planet Symposium], Proceedings of European Space Agency, Living Planet Symposium 2016 (5 2016).

[5] Weiss, A.-D., "Topographic position and landforms analysis," ESRI Users Conference (2001).

[6] Zevenbergen, L. and Thorne, C., "Quantitative analysis of land surface topography," Earth Surface Processes and Landforms 12(2), 47-56 (1987).

[7] "Unesco World Heritage List." http://whc.unesco.org/en/list (2 2017). (accessed 2/2017).

[8] "OpenStreetMap." https://www.openstreetmap.de/karte.html (2 2017). (accessed 2/2017). 